The Brock Review Volume 10 (2008)

(C) Brock University

\title{
Imaging the Urban Park
}

Kristine Thoreson

Alberta College of Art \& Design

Artist Statement: Much like the short-lived yet recurring space of a fairground, an urban park (in a Northern climate, at least) teems with activity for a few months each year and is then left to sit, empty and expectant, until next season's flurry of activity. Yet from one season to the next, I experience through them a continuity and familiarity that marks the passage of time. Thus I find that urban parks reflect, through cycles of presence and absence, the rhythm of life. In the twilight hours they elicit in me an anticipatory energy that seems to contain elements both of melancholy and exhilaration. As I explore each space, whether it is a wide-open lawn or a quiet pathway, I am reminded of the expectancy and anxiety of a darkened stage preceding or following a performance. It is this theatricality - this potential for narrative, alongside of anticipation, that attracts me to the quiet landscapes of early spring and winter. Thus, with this photographic project I have sought to create images that exhibit an awareness of space-the physical and the psychological, the mythic and the real. 


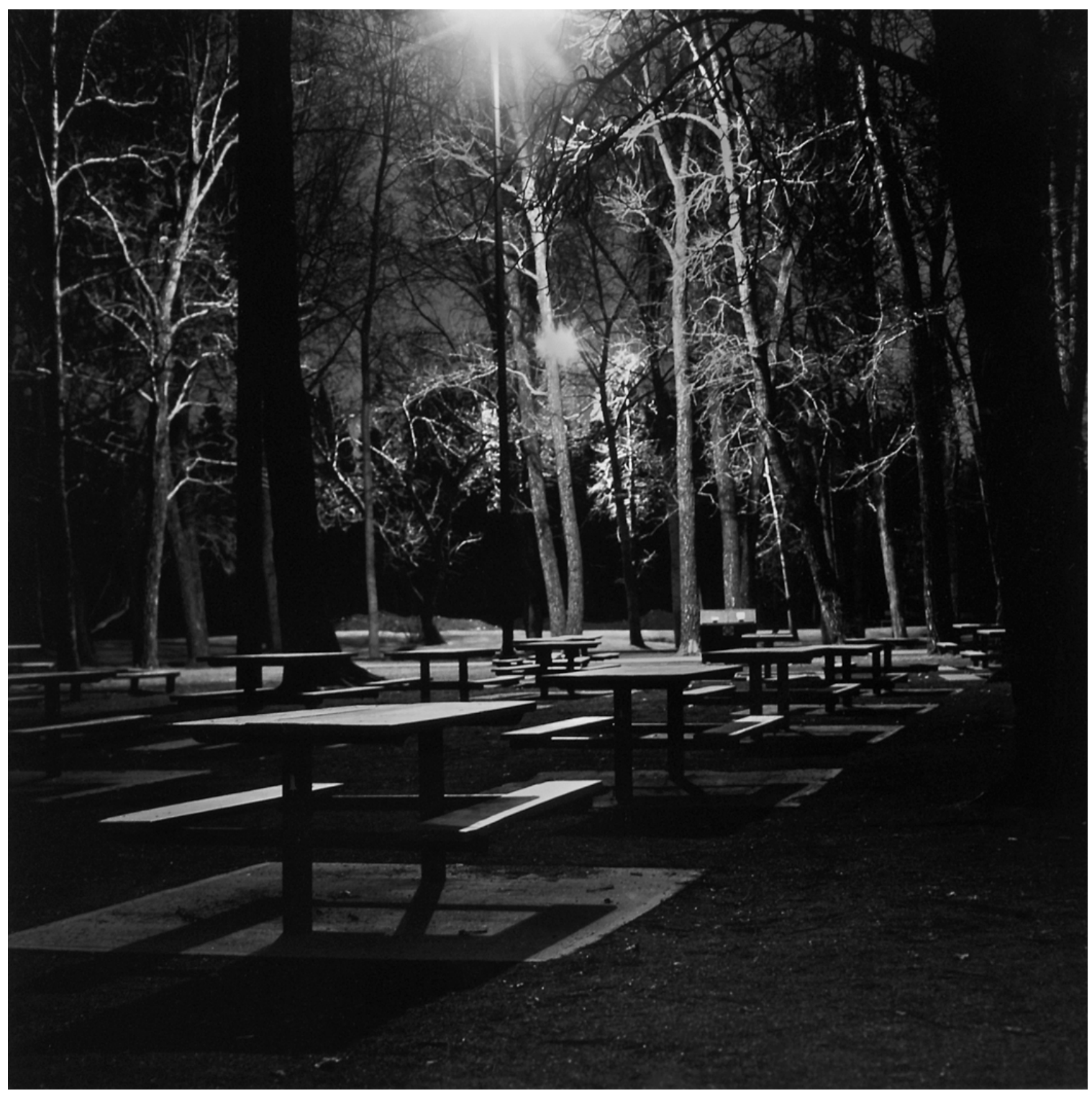

Kristine Thoreson, Picnic (2006-07) 


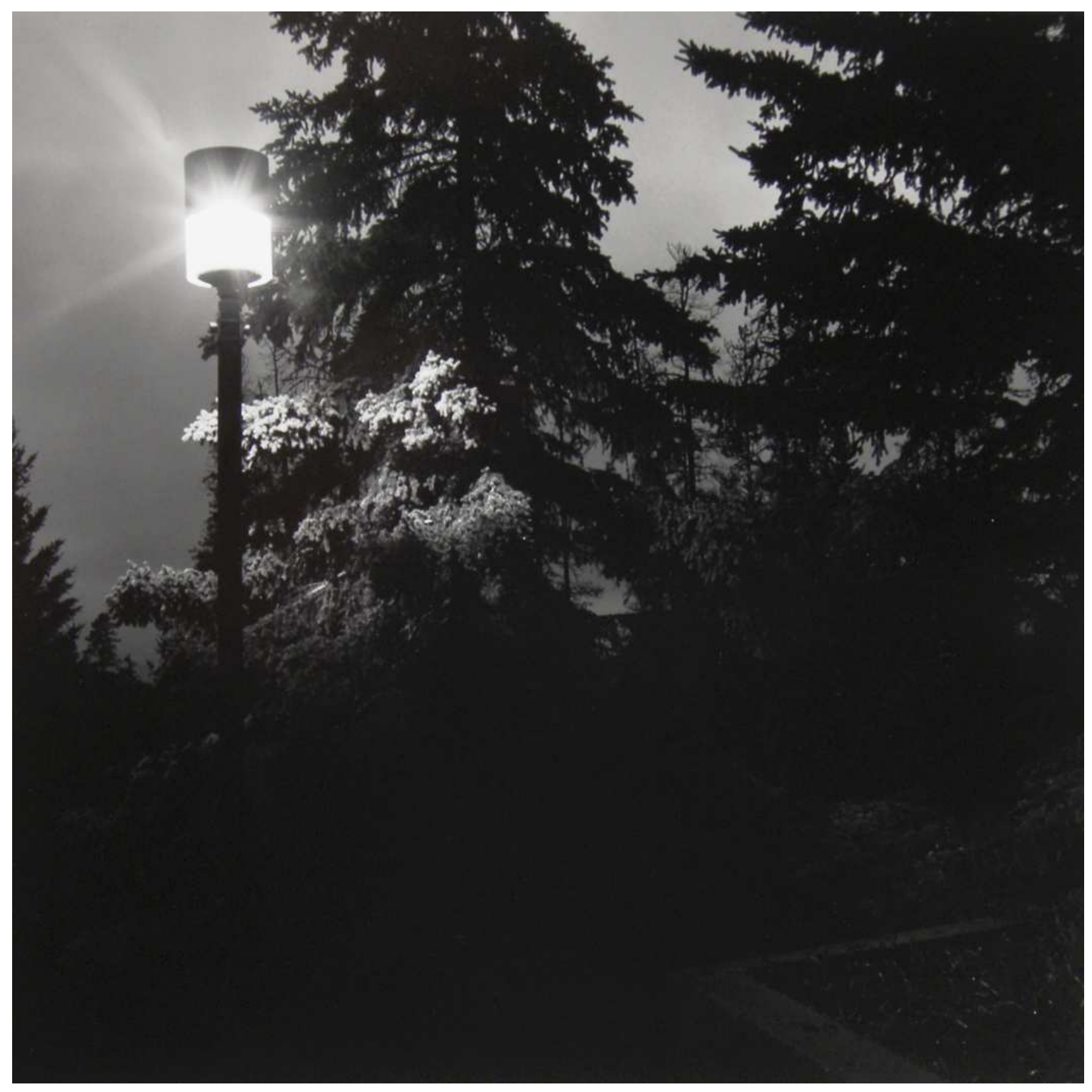

Kristine Thoreson, Looking West (2007) 


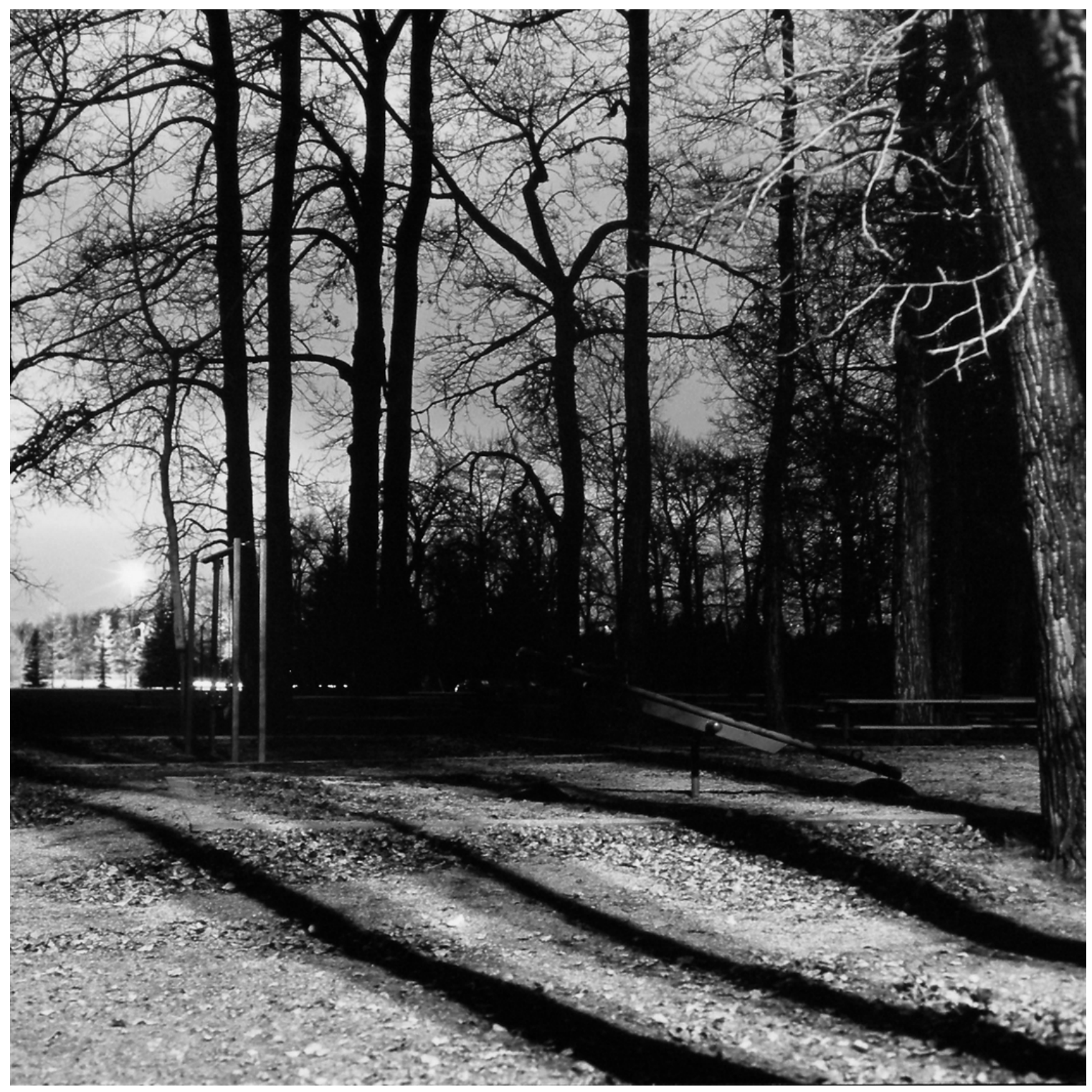

Kristine Thoreson, Bowness Park (2006-07) 


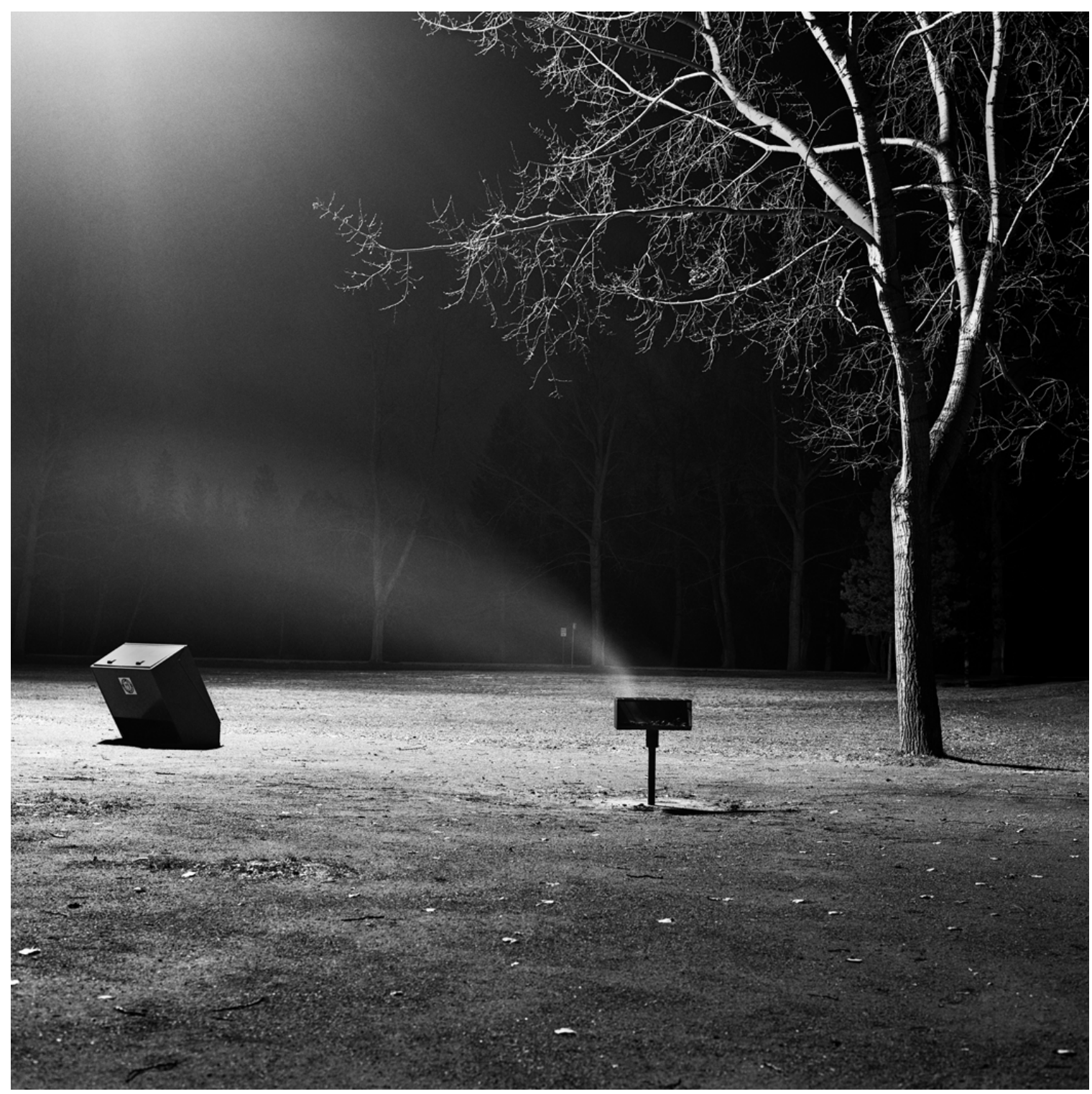

Kristine Thoreson, Night Stove (2006-07) 


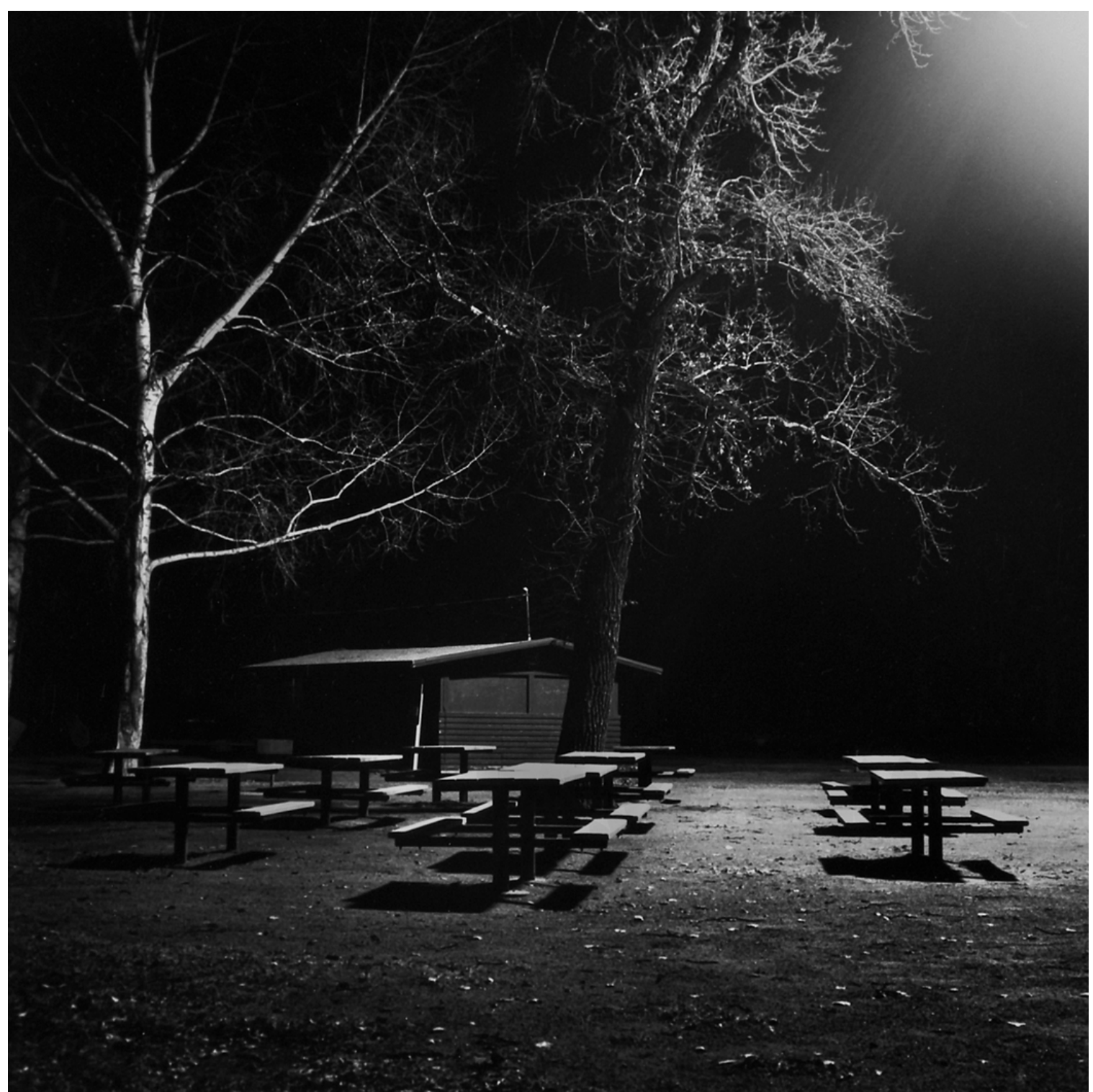

Kristine Thoreson, Group Camp (2006-07) 